\title{
A phase II study to determine the ability of gefitinib to reverse fluoropyrimidine resistance in metastatic colorectal cancer (the INFORM study)
}

\author{
J Stebbing', M Harrison ${ }^{2}$, R Glynne-Jones ${ }^{2}$, J Bridgewater ${ }^{3}$ and D Propper ${ }^{*, 4}$ \\ IImperial College, Imperial Healthcare, NHS Trust, Fulham Palace Road, London W6 8RF, UK; ${ }^{2}$ Department of Oncology, Mount Vernon Hospital, \\ Northwood HA6 2RN, UK; ${ }^{3}$ Department of Oncology, Middlesex Hospital, Royal Free and University College Medical School, Mortimer Street, London, \\ WIT 3AA, UK; ${ }^{4}$ Department of Medical Oncology, St Bartholomew's Hospital, West Smithfield, ECIA 7BE, London, UK
}

There are data suggesting that inhibition of epidermal growth factor receptor (EGFR) tyrosine kinase signalling may reverse resistance to fluoropyrimidine treatment. To investigate this further, the INFORM study was an open-label, non-comparative phase II study of gefitinib (Iressa, ZD I839; AstraZeneca, Wilmington, DE, USA) $250 \mathrm{mg}$ daily in combination with 5-fluorouracil (5-FU administered as an intravenous $400 \mathrm{mg} \mathrm{m}^{-2}$ bolus injection followed by $2800 \mathrm{mg} \mathrm{m}^{-2}$ infusion over $46 \mathrm{~h}$ and folinic acid administered as a $350 \mathrm{mg}$ infusion over $2 \mathrm{~h}$ ) every 2 weeks for up to 12 cycles in 24 patients with metastatic colorectal cancer refractory to previous fluoropyrimidine treatment. There were no objective responses. The stable disease rate was 37.5\% (95\% Cl: | $8.80,59.4$ I), median progression-free survival measured 116 days and overall survival was 226 days. Quality of life was unchanged compared to baseline values, and the commonest toxicities were diarrhoea, rash and fatigue with 7 out of 24 (29\%) patients having a grade 3 or 4 toxicity. Gefitinib does not sensitise patients with fluoropyrimidine refractory metastatic colorectal cancer to 5-FU chemotherapy. British Journal of Cancer (2008) 98, 7I6-719. doi:10.1038/sj.bjc.6604232 www.bjcancer.com

Published online 5 February 2008

(C) 2008 Cancer Research UK

Keywords: refractory; colorectal cancer; gefitinib; 5-fluorouracil; phase II

Large phase III randomised studies in metastatic colorectal cancer have demonstrated either response rate (Cunningham et al, 2004) or time to progression (Gibson et al, 2006; Saif and Cohenuram, 2006) advantages using monoclonal antibodies, such as cetuximab, directed specifically against the epidermal growth factor receptor (EGFR). Activation of the tyrosine kinase domain of this receptor catalyses autophosphorylation and subsequent proliferative and antiapoptotic cellular signal-transduction cascades (Hirata et al, 2002; Vincenzi et al, 2006). High EGFR expression is associated with resistance to conventional cytotoxic agents. In vitro data showed that where there is high constitutive EGFR phosphorylation, gefitinib synergistically sensitises conventional cytotoxic agent activity (Cho et al, 2006). A recent trial in 55 heavily pretreated patients who had received first-line oxaliplatin and secondline irinotecan-based regimens for metastatic colorectal carcinoma showed that cetuximab and irinotecan therapy led to clinically significant activity, suggesting that in some combinations EGFR inhibition can lead to chemosensitisation (Vincenzi et al, 2006). Others reported that cetuximab could reverse clinical resistance to irinotecan in colorectal cancer (Cunningham et al, 2004).

*Correspondence: Dr D Propper, Department of Medical Oncology, St Bartholomew's Hospital, ECIA 7BE, London, UK;

E-mail: d.j.propper@qmul.ac.uk

Received 15 October 2007; revised 13 December 2007; accepted 7 January 2008; published online 5 February 2008
Gefitinib is a small-molecule anilinoquinazoline inhibitor of EGFR tyrosine kinase signalling (Hirata et al, 2002; Cho et al, 2006) related chemically to erlotonib (Tarceva ${ }^{\circledR}$ ). In phase II studies, gefitinib monotherapy had significant antitumour activity in previously treated patients with advanced non-small-cell lung cancer (NSCLC). In phase III trials in NSCLC, however, gefitinib in combination with cytotoxic chemotherapy was not more efficacious than cytotoxic chemotherapy alone (Fukuoka et al, 2003; Johnson and Arteaga, 2003; Kris et al, 2003; Baselga, 2004; Giaccone et al, 2004; Thatcher et al, 2005). A number of phase I and II studies in metastatic colorectal carcinoma have investigated the effects of gefitinib in combination with standard 5-fluorouracil (5-FU)-based regimens, with response rates (where evaluated) ranging from 25 to $59 \%$ (Kuo et al, 2005; Cho et al, 2006; Hofheinz et al, 2006; Wolpin et al, 2006), although these trials did not include chemotherapy-resistant individuals. Gefitinib plus FOLFOX (oxaliplatin plus folinic acid and 5-FU) appeared to have significantly higher activity than reported in response to FOLFOX alone in similar historical populations (Kuo et al, 2005; Zampino et al, 2007).

A previous randomised phase II study has demonstrated that gefitinib has inhibitory effects on downstream regulators of cellular transformation in patients with previously treated colorectal cancer (Rothenberg et al, 2005). This, together with data showing that EGFR inhibition can reverse clinical resistance to chemotherapy (Cunningham et al, 2004), prompted the current study. In this trial, we investigated the efficacy and safety of a 
combination of daily dose of gefitinib and modified de Gramont 5-FU and folinic acid in patients with fluoropyrimidine refractory metastatic colorectal cancer to determine whether gefitinib could reverse resistance to 5 -FU chemotherapy.

\section{PATIENTS AND METHODS}

\section{Eligibility criteria}

Between March 2003 and September 2004, we enrolled patients with advanced measurable, histologically proven colorectal cancer who had received prior 5-FU or capecitabine either in the adjuvant setting and relapsing within 6 months of treatment or for locally advanced/metastatic disease and progressing through treatment. Patients with a World Health Organization (WHO) performance status $>2$, intracerebral disease, other serious conditions and a life expectancy of $<3$ months were excluded. Adequate bone marrow function defined as platelets $>100 \times 10^{9} / 1$, white blood cells $>3 \times 10^{9} / 1$, neutrophils $>1.5 \times 10^{9} / 1$, serum creatinine $<180 \mu \mathrm{moll}^{-1}$, ALT or AST $<2.5$ times the upper limit of normal or less than five times in the presence of liver metastases were required at trial entry.

All patients gave written informed consent and approval was obtained from the East London and the City Research Ethics Committee. The study followed the Declaration of Helsinki Principles and good clinical practise guidelines.

\section{Trial design}

All patients had a 2-week 'run-in' period (days 1-14) during which they received oral gefitinib (Iressa ${ }^{\mathbb{B}}$, AstraZeneca, Macclesfield, UK) $250 \mathrm{mg}$ once daily, before commencing combination chemotherapy with 5-FU administered as a $400 \mathrm{mg} \mathrm{m}^{-2}$ bolus injection over $5 \mathrm{~min}$ and as a $2800 \mathrm{mg} \mathrm{m}^{-2}$ infusion over $46 \mathrm{~h}$ and with folinic acid administered as a $350 \mathrm{mg}$ infusion over $2 \mathrm{~h}$, as the modified de Gramont regime every 14 days. In the absence of doselimiting toxicity (DLT), further 14-day treatment cycles could be administered up to a maximum of 12 cycles in total.

\section{Assessments}

Response Evaluation Criteria in Solid Tumours (RECIST) (Michaelis and Ratain, 2006) was used to assess objective tumour response by computerised tomography scan at baseline and then after every 8 weeks until progression. Toxicities were assessed by National Cancer Institute Common Toxicity Criteria (CTC) version 2.0 every 2 weeks. Disease-related symptoms and quality of life were compared to baseline using the Functional Assessment of Cancer Therapy - Colorectal (FACT-C) (Ramsey et al, 2000) at baseline, at the end of the run-in period and every 8 weeks thereafter. The questionnaire consisted of 37 statements, which were categorised into physical well-being (PWB), social/family well-being, emotional well-being, functional well-being and additional concerns. Each was analysed separately and a total FACT-C score was also calculated.

Duration of response was defined as the number of days from the first documented response of CR or PR until the earlier of either death or disease progression or the last on-study tumour assessment. Progression-free survival was defined as the number of days from the date of first dose of study treatment until the date of objective documented disease progression.

\section{Statistics}

A two-stage design incorporating the ad hoc rule of Green and Dahlberg (1992) was used to determine the number of patients, up to a maximum of 39 individuals, required to measure tumour response rates. The sample size was based on an overall power of
$90,5 \%$ significance level and a $2 \%$ false negative rate for the first stage. The baseline response rate on 5-FU alone was assumed to be $5 \%$, and a clinically relevant response rate of $20 \%$ on $5-\mathrm{FU} /$ gefitinib was defined. After 18 patients had entered the study and received the recommended dose, an interim analysis was to be performed to determine the objective response rate $(C R+P R)$. If no patients responded, the study was stopped. If one or more responses were observed, a further 21 patients were to be entered into the study. The hypothesis that the response rate was less than or equal to the baseline rate $(5 \%)$ was rejected if five or more responses were observed in total. Overall and progression-free survival were estimated using the Kaplan and Meier (1958) method.

\section{RESULTS}

From three recruiting centres in London, UK, a total of 24 individuals with a mean age of 64.3 years were enrolled, the majority with a WHO performance status of 0 or 1 (Table 1). All had received previous chemotherapy, the majority having had only one previous regimen that involved 5-FU (18 patients) or capecitabine (two patients). The remaining four individuals had received two prior 5-FU- and capecitabine-based regimens. All patients were analysed for safety and efficacy.

There were no objective tumour responses and all 24 patients discontinued treatment during the study. The main reason for

Table I Demographic and baseline patient characteristics

\begin{tabular}{|c|c|}
\hline Demographic or baseline characteristic & $\begin{array}{l}\text { Intention to treat/ } \\
\text { safety }(n=24)\end{array}$ \\
\hline \multicolumn{2}{|l|}{ Sex ( $n$ and $\%$ of patients) } \\
\hline Male & $14(58.3)$ \\
\hline Female & $10(41.7)$ \\
\hline \multicolumn{2}{|l|}{ Age (years) } \\
\hline Mean (s.d.) & $64.3(11.8)$ \\
\hline Range & $39-83$ \\
\hline \multicolumn{2}{|l|}{ Race ( $n$ and $\%$ of patients) } \\
\hline Caucasian & $20(83.3)$ \\
\hline Black & $3(12.5)$ \\
\hline Other & I (4.2) \\
\hline \multirow{2}{*}{\multicolumn{2}{|c|}{$\begin{array}{l}\text { Site of target lesion ( } n \text { and } \% \text { of patients) CT scans were } \\
\text { used in all cases, spiral CT for } 10 \text { patients }\end{array}$}} \\
\hline & \\
\hline $\begin{array}{l}\text { Lolorectal } \\
\text { Liver }\end{array}$ & $\begin{aligned} 2(8.3) \\
12(50.0)\end{aligned}$ \\
\hline Local/regional/staging lymph nodes & | (4.2) \\
\hline Distant metastatic lymph nodes & $2(8.3)$ \\
\hline Lung & $4(16.7)$ \\
\hline Peritoneum & । (4.2) \\
\hline Small bowel & I (4.2) \\
\hline Stomach & $3(12.5)$ \\
\hline Others (e.g., pericardial effusion) & $3(12.5)$ \\
\hline \multicolumn{2}{|l|}{ Longest diameter $(\mathrm{cm})$ of target lesion } \\
\hline Mean (s.d.) & $5.23(3.56)$ \\
\hline Non-target lesions present ( $n$ and $\%$ of patients) & | | (45.8) \\
\hline \multicolumn{2}{|l|}{ Prior therapy ( $n$ and $\%$ of patients) } \\
\hline Chemotherapy & $24(100)$ \\
\hline Radiotherapy & $7(29.2)$ \\
\hline Other cancer therapy & $10(41.7)$ \\
\hline \multicolumn{2}{|l|}{ WHO performance status ( $n$ and $\%$ of patients) } \\
\hline Normal activity & II (45.8) \\
\hline Restricted activity & $12(50.0)$ \\
\hline In bed $\leqslant 50 \%$ of the time & I (4.2) \\
\hline
\end{tabular}

$\mathrm{CT}=$ computerised tomography; $\mathrm{WHO}=$ World Health Organization. 
Table 2 The best overall response to FACT-C

\begin{tabular}{lcc}
\hline & $\begin{array}{c}\text { Evaluable for FACT-C } \\
\text { improvement }(\mathbf{n}=\mathbf{1 9})\end{array}$ & $\begin{array}{c}\text { Intention to } \\
\text { treat }(\mathbf{n}=\mathbf{2 4})\end{array}$ \\
\hline $\begin{array}{l}\text { Best overall response, } n(\%) \\
\text { Improved }\end{array}$ & $1(5.3)$ & $1(4.2)$ \\
No change & $2(10.5)$ & $2(8.3)$ \\
Worsened & $0(0)$ & $0(0)$ \\
Other & $16(84.2)$ & $21(87.5)$ \\
Improvement rate & & $1(4.2)$ \\
$N(\%)$ of patients & $1(5.3)$ & $(0.11,21.12)$ \\
$95 \%$ Cls & $(0.13,26.03)$ & \\
Control rate & & $3(12.5)$ \\
$N(\%)$ of patients & $3(15.8)$ & $(2.66,32.36)$ \\
$95 \%$ Cls & $(3.38,39.58)$ & $0(0)$ \\
Worsened rate & & $(0.00,14.25)$ \\
$N(\%)$ of patients & $0(0)$ & \\
$95 \%$ Cls & $(0.00,17.65)$ & \\
\hline
\end{tabular}

$\mathrm{Cl}=$ confidence interval; $\mathrm{FACT}-\mathrm{C}=$ Functional Assessment of Cancer Therapy Colorectal; $\mathrm{FWB}=$ functional well-being; $\mathrm{ITT}=$ intention to treat; $\mathrm{PWB}=$ physical well-being; $\mathrm{EWB}=$ emotional well-being; $S W B=$ social/family well-being. The PWB, EWB, SWB, FWB and additional concerns subscale scores and the FACT-C overall score were derived from the FACT-C questionnaire. The change in score from baseline to each visit during the treatment period was analysed by the Wilcoxon signed rank test for the ITT analysis set. The responses to each of the 10 additional concerns questions at each visit were also summarised for the ITT analysis set. The FACT-C best overall response was calculated, and the improvement rate, control rate and worsened rate were presented. The primary analysis population for the improvement rate included the subset of the ITT population with a baseline FACT-C score of 128 or less defined as the evaluable for FACT-C improvement set.

discontinuation was objective disease progression in 10 individuals $(42 \%)$. Five patients received the maximum 12 cycles. Stable disease, confirmed and sustained on two consecutive 8-weekly visits, was achieved in $37.5 \%$ (95\% CI: $18.80,59.41 ; 9$ out of 24 ) of patients. The Kaplan-Meier survival estimate for percentage of patients who were progression-free at 6 months was 35\% (95\% CI: $15.2,54.8)$. Progression-free survival time was estimated to be a median of 116 days (95\% CI: 72, 183). Five (20.8\%) patients were alive at 6 months in the intent-to-treat analysis set. The KaplanMeier overall survival estimate for the percentage of patients who were alive at 6 months was 54.2\% (95\% CI: 34.2, 74.1). Overall survival time was estimated to be a median of 226 days.

Nineteen (79\%) individuals completed the FACT-C scores (Table 2). There were no demonstrable changes from baseline throughout the study, with a median time to worsening of symptoms of 83 days (interquartile range 56-182 days). The only significant difference from baseline was the change in PWB from baseline to visit 7 (a mean deterioration of $4.67, P=0.03$ ), although it should be noted that this was based on just seven patients, so little should be drawn from this result. Overall, the FACT-C scores in response to the questions about their quality of life and additional concerns indicated that there had been little or no change from baseline.

All 24 patients experienced at least one adverse event; the majority of these were mild (CTC grade 1 or 2), and seven patients (29\%) had a CTC grade 3 or 4 adverse event that was considered to be drug-related (Table 3). Overall, diarrhoea, nausea, fatigue and vomiting were the mostly commonly reported toxicities, and 12 patients $(50 \%)$ discontinued owing to side effects. Dehydration and malaise were the only drug-related grade 3 or 4 adverse events reported by more than one patient; dehydration was reported by two patients (one related to gefitinib, one related to gefitinib/5-FU chemotherapy combination) and malaise was reported by two patients.
Table 3 Toxicity to gefitinib and 5-FU

\begin{tabular}{lcc}
\hline & \multicolumn{2}{c}{ Safety analysis set $(\mathbf{n}=\mathbf{2 4})$} \\
\cline { 2 - 3 } Toxicity, n (\%) & Grade I or 2 & Grade 3 or 4 \\
\hline Gefitinib & & \\
Rash & $5(20.8)$ & 0 \\
Diarrhoea & $3(12.5)$ & 0 \\
Erythema & $3(12.5)$ & 0 \\
5-FU & & 0 \\
Diarrhoea & $7(29.2)$ & $(4.2)$ \\
Stomatitis & $4(16.7)$ & 0 \\
Nausea & $4(16.7)$ & 0 \\
Alopecia & $3(12.5)$ & 0 \\
Erythema & $3(12.5)$ & 0 \\
Gefitinib/5-FU combination & & 0 \\
Diarrhoea & $4(16.7)$ & $(4.2)$ \\
Fatigue & $4(16.7)$ & \\
Nausea & $3(12.5)$ & \\
\hline
\end{tabular}

$5-F=5$-fluorouracil.

One patient, a 66-year-old female with a history of heart disease, died of a myocardial infarction after three cycles of treatment, and the infarction was presumed causally unrelated, although a post mortem was not performed.

\section{DISCUSSION}

In this study of individuals with fluoropyrimidine refractory progressive metastatic colorectal carcinoma, the addition of gefitinib to infusional 5-FU chemotherapy did not significantly reverse chemoresistance. No responses were observed, in contrast to other data that suggest that EGFR inhibition may reverse chemoresistance.

There was some evidence of disease control, with stable disease rate achieved in $9(37.5 \%)$ patients, and the median progressionfree survival time was 116 days, with a median overall survival of 226 days. The incidence and severity of drug-related adverse events showed that gefitinib in combination with 5-FU and folinic acid had an acceptable side effect profile and that synergistic diarrhoea and other toxicities were not evident.

The lack of responses observed here is compatible with the previous phase II study reported by Rothenberg et al (2005), in which 115 patients with metastatic colorectal cancer received either 250 or $500 \mathrm{mg}$ of daily gefitinib and only one partial response was observed, although a trend towards decreased posttreatment levels of activated Akt and Ki67 was observed in patients with a progression-free survival higher than the median. In a recent study combining gefitinib and irinotecan in patients with fluoropyrimidine-refractory, irinotecan-naive metastatic disease, there was no additional benefit from gefitinib (Chau et al, 2007). However, gefitinib plus FOLFOX appeared to have significantly higher activity than control populations treated with chemotherapy alone (Kuo et al, 2005; Zampino et al, 2007). Thus, it is conceivable that chemosensitisation reported with EGFR inhibition may be related to the cytotoxic used alongside gefitinib, although it is difficult to compare between different study populations.

The EGFR inhibitor monoclonal antibodies panitumumab and cetuximab have significant activity in chemorefractory colorectal cancer (Gibson et al, 2006; Saif and Cohenuram, 2006), and cetuximab was shown to reverse clinical resistance to irinotecan (Cunningham et al, 2004). The reasons for the difference between the results of the current study and those reported in refractory colorectal cancer with cetuximab are unclear. Although EGFR copy 
number and mutations were not studied here or in previous studies, higher (750 mg daily) doses of gefitinib also showed a lack of clinical activity (Mackenzie et al, 2005). In laboratory studies, gefitinib is reported to synergise with some but not other cytotoxic agents, and the addition of gefitinib to 5-FU resulted in synergistic apoptotic activity (Van Schaeybroeck et al, 2005). Sequence or schedule dependence is another possible explanation, as the synergistic effects of gefitinib with cytotoxic drugs (including 5FU) used in colorectal cancer may be dependent on the order of their administration (Magne et al, 2002; Xu et al, 2003; Shimoyama et al, 2006). Indeed, in vitro antagonistic effects of gefitinib on cell kill were observed when it was administered before oxaliplatin, likely because it inhibited the removal of DNA adducts (Xu et al, 2003). Others have reported similar antagonistic effects related to sequencing (Morelli et al, 2005).

\section{REFERENCES}

Baselga J (2004) Combining the anti-EGFR agent gefitinib with chemotherapy in non-small-cell lung cancer: how do we go from INTACT to impact? J Clin Oncol 22: 759-761

Chau I, Cunningham D, Hickish T, Massey A, Higgins L, Osborne R, Botwood N, Swaisland A (2007) Gefitinib and irinotecan in patients with fluoropyrimidine-refractory, irinotecan-naive advanced colorectal cancer: a phase I-II study. Ann Oncol 18: 730-737

Cho CD, Fisher GA, Halsey J, Sikic BI (2006) Phase I study of gefitinib, oxaliplatin, 5-fluorouracil, and leucovorin (IFOX) in patients with advanced solid malignancies. Invest New Drugs 24: 117-123

Cunningham D, Humblet Y, Siena S, Khayat D, Bleiberg H, Santoro A, Bets D, Mueser M, Harstrick A, Verslype C, Chau I, Van Cutsem E (2004) Cetuximab monotherapy and cetuximab plus irinotecan in irinotecanrefractory metastatic colorectal cancer. $N$ Engl J Med 351: 337-345

Fukuoka M, Yano S, Giaccone G, Tamura T, Nakagawa K, Douillard JY, Nishiwaki Y, Vansteenkiste J, Kudoh S, Rischin D, Eek R, Horai T, Noda K, Takata I, Smit E, Averbuch S, Macleod A, Feyereislova A, Dong RP, Baselga J (2003) Multi-institutional randomized phase II trial of gefitinib for previously treated patients with advanced non-small-cell lung cancer (The IDEAL 1 Trial) [corrected]. J Clin Oncol 21: 2237-2246

Giaccone G, Herbst RS, Manegold C, Scagliotti G, Rosell R, Miller V, Natale RB, Schiller JH, Von Pawel J, Pluzanska A, Gatzemeier U, Grous J, Ochs JS, Averbuch SD, Wolf MK, Rennie P, Fandi A, Johnson DH (2004) Gefitinib in combination with gemcitabine and cisplatin in advanced non-small-cell lung cancer: a phase III trial - INTACT 1. J Clin Oncol 22: 777-784

Gibson TB, Ranganathan A, Grothey A (2006) Randomized phase III trial results of panitumumab, a fully human anti-epidermal growth factor receptor monoclonal antibody, in metastatic colorectal cancer. Clin Colorectal Cancer 6: 29-31

Green SJ, Dahlberg S (1992) Planned versus attained design in phase II clinical trials. Stat Med 11: 853-862

Hirata A, Ogawa S, Kometani T, Kuwano T, Naito S, Kuwano M, Ono M (2002) ZD1839 (Iressa) induces antiangiogenic effects through inhibition of epidermal growth factor receptor tyrosine kinase. Cancer Res 62: $2554-2560$

Hofheinz RD, Kubicka S, Wollert J, Arnold D, Hochhaus A (2006) Gefitinib in combination with 5-fluorouracil (5-FU)/folinic acid and irinotecan in patients with 5 -FU/oxaliplatin-refractory colorectal cancer: a phase I/II study of the Arbeitsgemeinschaft fur Internistische Onkologie (AIO). Onkologie 29: $563-567$

Johnson DH, Arteaga CL (2003) Gefitinib in recurrent non-small-cell lung cancer: an IDEAL trial? J Clin Oncol 21: 2227-2229

Kaplan E, Meier P (1958) Nonparametric estimation from incomplete observations. J Am Stat Assoc 53: 457-481

Kris MG, Natale RB, Herbst RS, Lynch Jr TJ, Prager D, Belani CP, Schiller JH, Kelly K, Spiridonidis H, Sandler A, Albain KS, Cella D, Wolf MK, Averbuch SD, Ochs JJ, Kay AC (2003) Efficacy of gefitinib, an inhibitor of the epidermal growth factor receptor tyrosine kinase, in symptomatic patients with non-small cell lung cancer: a randomized trial. Jama 290: 2149-2158

Kuo T, Cho CD, Halsey J, Wakelee HA, Advani RH, Ford JM, Fisher GA, Sikic BI (2005) Phase II study of gefitinib, fluorouracil, leucovorin, and oxaliplatin therapy in previously treated patients with metastatic colorectal cancer. J Clin Oncol 23: 5613-5619

Mackenzie MJ, Hirte HW, Glenwood G, Jean M, Goel R, Major PP, Miller Jr WH, Panasci L, Lorimer IA, Batist G, Matthews S, Douglas L, Seymour L
In summary, this study does not show evidence that EGFR inhibition using the oral tyrosine kinase inhibitor gefitinib significantly reverses clinical resistance to 5-FU. This contrasts with laboratory studies and also with clinical studies of EGFR inhibition using monoclonal antibodies in refractory colorectal cancer. The reasons for the differences in clinical outcomes between EGFR tyrosine kinase inhibition by small molecules and by monoclonal antibodies remain unclear.

\section{ACKNOWLEDGEMENTS}

This study was supported by AstraZeneca. All authors contributed to patient enrolment, study design, analysis of data and paper preparation.

(2005) A phase II trial of ZD1839 (Iressa) $750 \mathrm{mg}$ per day, an oral epidermal growth factor receptor-tyrosine kinase inhibitor, in patients with metastatic colorectal cancer. Invest New Drugs 23: 165-170

Magne N, Fischel JL, Dubreuil A, Formento P, Marcie S, Lagrange JL, Milano G (2002) Sequence-dependent effects of ZD1839 ('Iressa') in combination with cytotoxic treatment in human head and neck cancer. Br J Cancer 86: 819-827

Michaelis LC, Ratain MJ (2006) Measuring response in a post-RECIST world: from black and white to shades of grey. Nat Rev Cancer 6: 409-414

Morelli MP, Cascone T, Troiani T, De Vita F, Orditura M, Laus G, Eckhardt SG, Pepe S, Tortora G, Ciardiello F (2005) Sequence-dependent antiproliferative effects of cytotoxic drugs and epidermal growth factor receptor inhibitors. Ann Oncol 16(Suppl 4): iv61 - iv68

Ramsey SD, Andersen MR, Etzioni R, Moinpour C, Peacock S, Potosky A, Urban N (2000) Quality of life in survivors of colorectal carcinoma. Cancer 88: $1294-1303$

Rothenberg ML, LaFleur B, Levy DE, Washington MK, Morgan-Meadows SL, Ramanathan RK, Berlin JD, Benson III AB, Coffey RJ (2005) Randomized phase II trial of the clinical and biological effects of two dose levels of gefitinib in patients with recurrent colorectal adenocarcinoma. J Clin Oncol 23: 9265-9274

Saif MW, Cohenuram M (2006) Role of panitumumab in the management of metastatic colorectal cancer. Clin Colorectal Cancer 6: 118-124

Shimoyama T, Koizumi F, Fukumoto H, Kiura K, Tanimoto M, Saijo N, Nishio K (2006) Effects of different combinations of gefitinib and irinotecan in lung cancer cell lines expressing wild or deletional EGFR. Lung Cancer 53: 13-21

Thatcher N, Chang A, Parikh P, Rodrigues Pereira J, Ciuleanu T, von Pawel J, Thongprasert S, Tan EH, Pemberton K, Archer V, Carroll K (2005) Gefitinib plus best supportive care in previously treated patients with refractory advanced non-small-cell lung cancer: results from a randomised, placebo-controlled, multicentre study (Iressa Survival Evaluation in Lung Cancer). Lancet 366: 1527-1537

Van Schaeybroeck S, Karaiskou-McCaul A, Kelly D, Longley D, Galligan L, Van Cutsem E, Johnston P (2005) Epidermal growth factor receptor activity determines response of colorectal cancer cells to gefitinib alone and in combination with chemotherapy. Clin Cancer Res 11: $7480-7489$

Vincenzi B, Santini D, Rabitti C, Coppola R, Beomonte Zobel B, Trodella L, Tonini G (2006) Cetuximab and irinotecan as third-line therapy in advanced colorectal cancer patients: a single centre phase II trial. $\mathrm{Br} J$ Cancer 94: 792 - 797

Wolpin BM, Clark JW, Meyerhardt JA, Earle CC, Ryan DP, Enzinger PC, Zhu AX, Blaszkowsky L, Battu S, Fuchs CS (2006) Phase I study of gefitinib plus FOLFIRI in previously untreated patients with metastatic colorectal cancer. Clin Colorectal Cancer 6: 208-213

Xu JM, Azzariti A, Colucci G, Paradiso A (2003) The effect of gefitinib (Iressa, ZD1839) in combination with oxaliplatin is schedule-dependent in colon cancer cell lines. Cancer Chemother Pharmacol 52: 442-448

Zampino MG, Magni E, Massacesi C, Zaniboni A, Martignetti A, Zorzino L, Lorizzo K, Santoro L, Boselli S, de Braud F (2007) First clinical experience of orally active epidermal growth factor receptor inhibitor combined with simplified FOLFOX6 as first-line treatment for metastatic colorectal cancer. Cancer 110: $752-758$ 